\title{
Comparison of sealers used in laparoscopic cholecystectomy for cystic duct closure: An ex vivo study
}

\author{
(1) Aziz Ahmet Surel, ${ }^{1}$ @ Burak Kavlakoğlu² \\ 'Department of General Surgery, Ankara City Hospital, Ankara, Turkey \\ ${ }^{2}$ Department of General Surgery, Bahçeşehir University, İstanbul, Turkey
}

\begin{abstract}
Introduction: To compare the safety and efficacy of Harmonic scalpel (HS) and Plasmakinetic (PK) sealer in achieving safe closure of the cystic ducts ex-vivo after the laparoscopic cholecystectomy.

Materials and Methods: In this prospective study, 90 patients with symptomatic gallstone disease were operated using laparoscopic technic. Then gallbladders were divided into three groups $(n=30)$. In all groups, gallbladders were removed with surgical clips. After the gallbladders removed, in first group, cystic ducts remain clipped (SC). In second and third groups, cystic ducts were sealed with HS and PK distally after the surgical clips removed. Then, twenty-gauge catheters were applied to fundic part of gallbladder and gallbladders filled with saline. An increasing pressure was applied through a sphygmomanometer. Bursting pressures were measured using invasive arterial blood pressure measurement device and measured systolic pressures were accepted bursting pressure. After bursting pressures were measured in three groups, results were written down to the SPSS table. Differences between HSvsSC, HSvsPK and SCvsPK groups were calculated using paired-samples t-test.

Results: In this study, the mean cystic duct bursting pressures were $332.46 \pm 4.62 \mathrm{~mm} \mathrm{Hg}$ with SC, $326.56 \pm 4.53$ $\mathrm{mmHg}$ with PK and $343.06 \pm 4.28 \mathrm{~mm} \mathrm{Hg}$ with HS. Differences in the mean cystic duct bursting pressures between HS vs. SC and HS vs. PK groups were indicated HS's superiority ( $p=0.046$ and $p=0.026$, respectively). On the contrary, SC vs. PK group was not indicated PK's advantage; however, PK was found safely as much as SC.

Conclusion: HS and PK sealer could be an alternative and safe method for cystic duct closure, avoiding the clip displacement and migration of the clip. Single device usage was one of the most important advantages of this technique. Thus, intraabdominal organ injuries will be lessened.
\end{abstract}

Keywords: Closure; cystic duct; energy devices.

\section{Introduction}

Laparoscopic cholecystectomy (LC) is the gold standard surgical method for the treatment of gallstones. ${ }^{[1,2]}$ In laparoscopic cholecystectomy, cystic duct and artery are secured with surgical clips (SC). Intracorporeal ligation is usually superior to extracorporeal knotting. Most studies describe separate and multiple ligations of cystic duct and artery, which are viewed as technically demanding 
and time consuming. The widely used method for the closure of the cystic duct and artery is titanium SC. ${ }^{[3,4]} \mathrm{SC}$ closure seems to be the safest method, but it has some disadvantages like; leakage due to clip displacement, fall from the applicator and migration to the biliary duct or duodenum. ${ }^{[5-7]}$ Therefore, some other techniques are described such as suture ligation, Harmonic Scalpel (HS), LigaSure and Plasma Kinetic (PK) sealer to close the cystic duct and artery. ${ }^{[8-10]}$ Although laparoscopic cystectomy is a safe method, complications related to the devices and techniques used have been reported. ${ }^{[11,12]}$ With the technological developments, many sealing devices have become available in laparoscopy.

PK (Gyrus, Minneapolis, MN) is a bipolar energy source used to cover veins smaller than $5 \mathrm{~mm} \cdot{ }^{[13]}$ This bipolar electrosurgical device uses plasma kinetic technology to deliver a high current and very low voltage to the tissue. The vessel is sealed by denaturing the protein within the vessel walls, forming a coagulum which occludes the lumen. ${ }^{[14]}$ A blade can be manually deployed through the forceps to transect tissue.

The HS (Ethicon, Cincinnati, $\mathrm{OH}$ ) is a high frequency ultrasonic transducer. The active titanium blade vibrates at 55.000 cycles per second. The resulting mechanical energy causes a breakdown of protein in tissues which creates a coagulum. Vessel and tissue sealing is dependent on the power setting as well as the pressure exerted, the formation of the coagulum and tissue tension. The active blade of the HS can also be used as a knife. Harmonic Scalpel is FDA approved to seal vessels up to $5 \mathrm{~mm} \cdot{ }^{[15]}$

\section{Materials and Methods}

In this prospective ex-vivo study, ninety patients undergoing elective laparoscopic cholecystectomy were included after the approval of Abdurrahman Yurtaslan Onkoloji local ethics committee. Perforated and unintact sacs, gallstones impacted in cystic duct, history of cholecystitis and previous abdominal surgery were used as study exclusion criteria. Demographic data of the patient and the operation were recorded for statistical evaluation.

\section{Surgical Technique}

Laparoscopically, cystic artery and cystic canal were visualized by dissection of Calot triangle. Subsequently, the cystic artery and cystic canal were closed with single titanium clips from the proximal and distal part. Subsequently, the gallbladder was removed from the sac bed by dissection and the standard cholecystectomy was performed and the sac was taken out from the body. Those without any perforation or damage in the gallbladder and with cystic duct diameter lower than $5 \mathrm{~mm}$ were divided into 3 groups in a row. In Group 1, the cystic duct was closed with a single titanium SC; in Group 2, the cystic duct titanium clip was removed and sealed with PK. In Group 3, the cystic channel titanium clip was removed and sealed with HS. The sealing level with HS was low energy level (Level 2) and PK sealing level was also low energy level (Vapor pulse 3=35W). Then, 20-gauge iv cannula was placed in the fundus of the gallbladder and drowned with 3/0 silk suture to prevent leakage. Subsequently, the iv cannula was connected to the invasive arterial pressure measurement monitor via a 3-way tap and filled with saline until the sac wall was stretched. Then the sphygmomanometer was attached around the gallbladder and the pressure inside the gallbladder was gradually increased (Fig. 1). In all three groups, the last pressure value before the cystic duct was opened and the pressure followed simultaneously on the monitor decreased, was recorded as bursting pressure. Than, the bursting pressures of Groups were compared to each other.

\section{Statistical Analysis}

Statistical analysis was performed with SPSS 10.0 version (SPSS, Inc., Chicago, IL). Comparison between groups was done using paired-sample t-test.

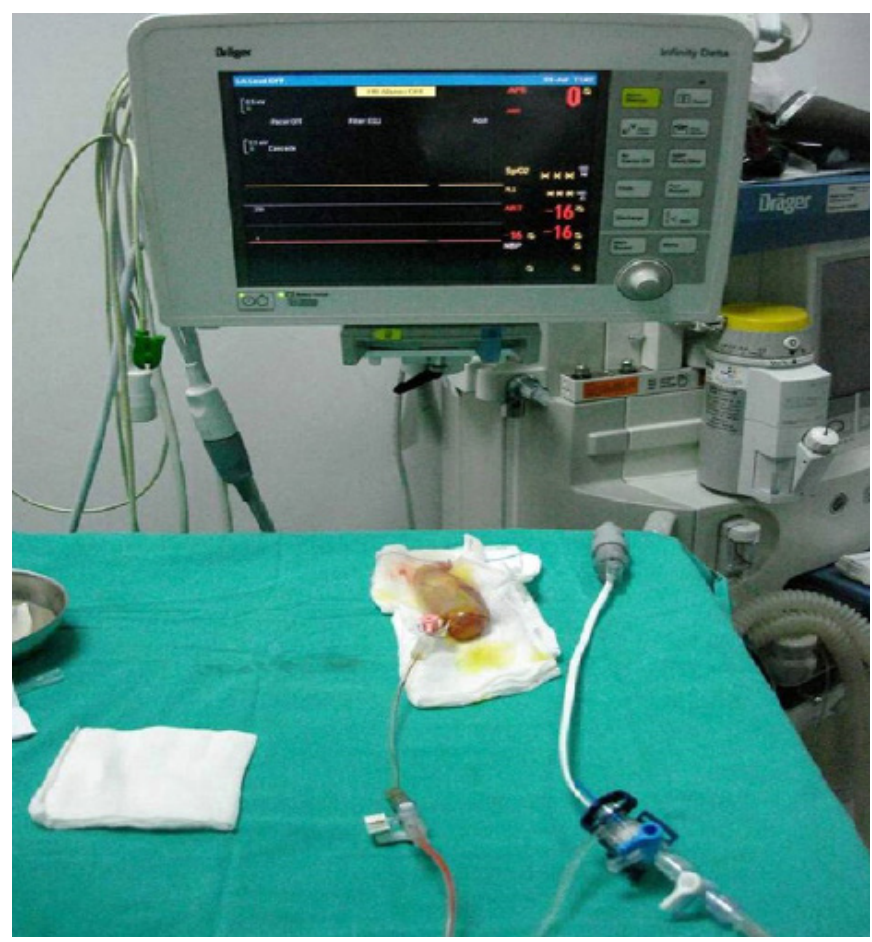

Figure 1. Equipment used for the study. 


\section{Results}

A total of 90 patients were operated on in this study. None of the patients included in the study had complications or injuries in the gallbladder. There was no statistical difference in demographic data such as age and gender among the patients.

Bursting pressures in the three groups included in the study were higher than the normal contraction pressure of the gallbladder. The mean cystic duct bursting pressures were $332.46 \pm 4.62 \mathrm{mmHg}$ in SC group, $326.56 \pm 4.53$ $\mathrm{mmHg}$ in PK group and $343.06 \pm 4.28 \mathrm{mmHg}$ in HS group (Table 1). Compared to SC group; PK group appears to be as effective as surgical clips used as a standard method for cystic duct closure. However, when evaluated in terms of bursting pressures, superiority to surgical clips was not detected. In the HS group in which the cystic canal was closed with an ultrasonic dissector, the average burst pressures determined were higher than the SC group and this was found statistically significant ( $\mathrm{p}=0.046)$. In comparison to groups PK and HS among themselves in terms of cystic canal burst pressures; In the group whose cystic duct was closed with HS, the bursting pressures were significantly higher than the group covered with the cystic duct PK $(\mathrm{p}=0.026)$ (Table 2).

\section{Discussion}

Laparoscopic cholecystectomy is the gold standard technique in general surgery practice instead of open surgery ${ }^{[1}$, ${ }^{2]}$ However, there are difficulties and complications related to the surgical instruments used in this technique. The most important stage of this surgery is the closure of the cystic duct. Surgical clips are the most commonly used surgical instruments for closing the cystic duct. ${ }^{[16]}$ Although SC are very safe, serious complications, such as bile leakage, can occur in cases where the clips displacement or open. ${ }^{[17]}$

Alternatively, sutures and sealer surgical instruments can be used to close the biliary tract. These devices used
Table 2. Comparison of cystic duct bursting pressures between groups

\begin{tabular}{llll} 
Groups & \multicolumn{2}{c}{$\begin{array}{c}\text { Bursting pressures } \\
(\mathrm{mmHg})\end{array}$} & p \\
\cline { 2 - 3 } & Mean & SD & \\
\hline Group 1-3 & & & \\
SC & 332.46 & 4.62 & 0.046 \\
HS & 343.06 & 4.28 & \\
Group 2-3 & & & \\
PK & 326.56 & 4.53 & 0.026 \\
HS & 343.06 & 4.28 & \\
Group 1-2 & & & \\
SC & 332.46 & 4.62 & 0.338 \\
PK & 326.56 & 4.53 & \\
\hline
\end{tabular}

SD: Standard deviation.

in sealing are also used in dissection and use monopolar, bipolar and ultrasonic energy sources. ${ }^{[18-20]}$ Monopolar dissectors are the oldest instruments used since the beginning of laparoscopy. The main disadvantage of monopolar energy sources is the uncontrolled spread of energy throughout the body. Serious complications such as biliary leak, biliary fistula, and stenosis may occur as a result of electrothermal damage due to this uncontrolled spread and cannot use for cystic duct closure. ${ }^{[11,12]}$

PK is a $5 \mathrm{~mm}$ diameter bipolar hand tool used frequently in laparoscopy. There are no feedback sensors, so its application is made on visual basis. The most important disadvantages of PK we use in our study are; lateral thermal damage and jaws sticking to the tissue after hemostasis. ${ }^{[21]}$ Pietrow et al. ${ }^{[22]}$ examined the effectiveness of PK in closing the renal vascular structures, they found the device as effective as SC in this respect and used the $35 \mathrm{~W}$ mode (Vapor pulse 3) for sealing, similar to what we used in our study. In our study, PK was found to be as effective as SC in cystic canal closure. However, our study was ex vivo

\section{Table 1. Cystic duct bursting pressures of the groups}

\begin{tabular}{|c|c|c|c|c|c|c|}
\hline \multirow[t]{2}{*}{ Parameters } & \multicolumn{2}{|c|}{$\begin{array}{c}\text { Group } 1 \text { (SC) } \\
n=30\end{array}$} & \multicolumn{2}{|c|}{$\begin{array}{c}\text { Group } 2(P K) \\
n=30\end{array}$} & \multicolumn{2}{|c|}{$\begin{array}{c}\text { Group } 3(\mathrm{HS}) \\
\mathrm{n}=\mathbf{3 0}\end{array}$} \\
\hline & Mean & SD & Mean & SD & Mean & SD \\
\hline Bursting pressure, $\mathrm{mmHg}$ & 332.46 & 4.62 & 326.56 & 4.53 & 343.06 & 4.28 \\
\hline
\end{tabular}


and no histological examination in terms of the rate of thermal damage is a limiting factor.

The HS is a surgical instrument used to simultaneously cut and cauterize tissue. Ultrasonic energy is used in HS where ultrasonic energy is converted to mechanical energy at the active blade. ${ }^{[23]}$ While the coagulation and cutting temperatures of ultrasonic devices are 60-100 degrees, this temperature can increase to 150-200 degrees in electrothermal devices. ${ }^{[24]}$ The use of HS during dissection of the Calot triangle and dissection of the gallbladder from the liver has also become quite common. Thus; Less smoke formation during sealing, less gallbladder perforation and adjacent tissue damage, less post-operative pain and postoperative drainage rates are reported. ${ }^{[20]}$ Similar to PK, since HS does not have biofeedback sensors, sealing is only done on visual ground. Matthews et al. ${ }^{[25]} \mathrm{com}$ pared the effectiveness of HS, LigaSure and SC in cystic canal sealing. As a result, they reported that LigaSure was more successful ex vivo in sealing of cystic ducts, but in an animal study in pigs, they failed sealing with HS and LigaSure. Similar to our study, Foschi et al. ${ }^{[26]}$ removed SC after laparoscopic cholecystectomy and closed the cystic canal with HS ex vivo. However, since they opened the gallbladder and inserted a foley catheter, they obtained lower burst pressures $(168+/-47 \mathrm{mmHg})$ from our study due to the disruption of the sac integrity. Westervelt et al. ${ }^{[9]}$ encountered no bile leakage with HS closure of the cystic duct in their 100 patients cholecystectomy series. In a similar study, Huscher et al. ${ }^{[27]}$ sealed the cystic duct with HS, they found the burst pressure $320 \mathrm{mmHg}$ almost similar to ours.

In our study HS was found as safe as SC and the worst bursting pressures found in PK group. However, the mean PK bursting pressures were higher than common bile duct pressure and Oddi sphincter pressure. Although PK and HS are expensive devices to seal the cystic channel, we think that their use at dissection also increases the cost effectiveness.

\section{Conclusion}

Our study indicates that HS is more effective than PK and both of them are safe and effective as SC. The main advantage of HS and PK is less organ injury due to single device usage during laparoscopy. The usage of HS and PK are good alternative to Surgical clips.

\section{Disclosures}

Ethichs Committee Approval: The study was approved by the Abdurrahman Yurtaslan Oncology Training and Research Hospital Local Ethics Commitee with approval number 2010-06-21.

Peer-review: Externally peer-reviewed.

Conflict of Interest: None declared.

Authorship Contributions: Concept - A.A.S.; Design A.A.S., B.K.; Supervision - B.K.; Materials - A.A.S.; Data collection and/or processing - A.A.S.; Analysis and/or interpretation - B.K.; Literature search - A.A.S., B.K.; Writing - A.A.S.; Critical review - B.K.

\section{References}

1. Keus F, Broeders IA, van Laarhoven CJ. Gallstone disease: Surgical aspects of symptomatic cholecystolithiasis and acute cholecystitis. Best Pract Res Clin Gastroenterol 2006;20:1031-51. [CrossRef]

2. Mufti TS, Ahmad S, Naveed D, Akbar M, Zafar A. Laparoscopic cholecystectomy: an early experience at Ayub Teaching Hospital Abbottabad. J Ayub Med Coll Abbottabad. 2007;19:42-4.

3. Yano H, Okada K, Kinuta M, Nakano Y, Tono T, Matsui S, et al. Efficacy of absorbable clips compared with metal clips for cystic duct ligation in laparoscopic cholecystectomy. Surg Today 2003;33:18-23. [CrossRef]

4. Herline AJ, Fisk JM, Debelak JP, Shull HJ Jr, Chapman WC. Surgical clips: a cause of late recurrent gallstones. Am Surg 1998;64:845-8.

5. Hanazaki K, Igarashi J, Sodeyama H, Matsuda Y. Bile leakage resulting from clip displacement of the cystic duct stump: a potential pitfall of laparoscopic cholecystectomy. Surg Endosc 1999;13:168-71. [CrossRef]

6. Kuroki T, Tajima Y, Tsuneoka N, Kitasato A, Adachi T, Mishima $\mathrm{T}$, et al. Biliary navigation surgery using endoscopic nasobiliary drainage tube for the prevention of bile duct injury in laparoscopic cholecystectomy. Hepatogastroenterology 2007;54:1018-9.

7. Klein RD, Jessup G, Ahari F, Connolly RJ, Schwaitzberg SD. Comparison of titanium and absorbable polymeric surgical clips for use in laparoscopic cholecystectomy. Surg Endosc 1994;8:753-8. [CrossRef]

8. Wang CJ, Yuen LT, Yen CF, Lee CL, Soong YK. Comparison of the efficacy of the pulsed bipolar system and conventional bipolar electrosurgery in laparoscopically assisted vaginal hysterectomy. J Laparoendosc Adv Surg Tech A 2005;15:361-4. [CrossRef]

9. Westervelt J. Clipless cholecystectomy: broadening the role of the harmonic scalpel. JSLS 2004;8:283-5.

10. Shamiyeh A, Vattay P, Tulipan L, Schrenk P, Bogner S, Danis $\mathrm{J}$, et al. Closure of the cystic duct during laparoscopic cholecystectomy with a new feedback-controlled bipolar sealing 
system in case of biliary obstruction--an experimental study in pigs. Hepatogastroenterology 2004;51:931-3.

11. Humes DJ, Ahmed I, Lobo DN. The pedicle effect and direct coupling: delayed thermal injuries to the bile duct after laparoscopic cholecystectomy. Arch Surg 2010;145:96-8.

12. Kapoor VK. Management of bile duct injuries: a practical approach. Am J Surg 2009;75:1157-60. [CrossRef]

13. Carbonell AM, Joels CS, Kercher KW, Matthews BD, Sing RF, Heniford BT. A comparison of laparoscopic bipolar vessel sealing devices in the hemostasis of small-, medium-, and large-sized arteries. J Laparoendosc Adv Surg Tech A 2003;13:377-80. [CrossRef]

14. Hruby GW, Marruffo FC, Durak E, Collins SM, Pierorazio P, Humphrey PA, et al. Evaluation of surgical energy devices for vessel sealing and peripheral energy spread in a porcine model. J Urol 2007;178:2689-93. [CrossRef]

15. El Nakeeb A, Askar W, El Lithy R, Farid M. Clipless laparoscopic cholecystectomy using the Harmonic scalpel for cirrhotic patients: a prospective randomized study. Surg Endosc 2010;24:2536-41. [CrossRef]

16. Rohatgi A, Widdison AL. An audit of cystic duct closure in laparoscopic cholecystectomies. Surg Endosc 2006;20:875-7.

17. Ojima H, Yamauchi $H$, Yamaki E, Idetu A, Hosouchi $Y$, Nishida $Y$, et al. Management of bile leakage caused by clip displacement from cystic duct stumps. Hepatogastroenterology 2007;54:28-31.

18. Schulze S, Krisitiansen VB, Fischer Hansen B, Rosenberg J. Sealing of cystic duct with bipolar electrocoagulation. Surg Endosc 2002;16:342-4. [CrossRef]

19. Wetter LA, Payne JH, Kirshenbaum G, Podoll EF, Bachinsky T, Way LW. The ultrasonic dissector facilitates laparoscopic cholecystectomy. Arch Surg 1992;127:1195-9. [CrossRef]

20. Tebala GD. Three-port laparoscopic cholecystectomy by harmonic dissection without cystic duct and artery clipping. Am J Surg 2006;191:718-20. [CrossRef]

21. Kapoor VK. Management of bile duct injuries: a practical approach. Am J Surg 2009;75:1157-60. [CrossRef]

22. Cho HY, Choi KJ, Lee YL, Chang KH, Kim HB, Park SH. Comparison of two bipolar systems in laparoscopic hysterectomy. JSLS 2012;16:456-60. [CrossRef]

23. Pietrow $P K$, Weizer AZ, L'Esperance JO, Auge BK, Silverstein A, Cummings $T$, et al. PlasmaKinetic bipolar vessel sealing: burst pressures and thermal spread in an animal model. $J$ Endourol 2005;19:107-10. [CrossRef]

24. Litta $\mathrm{P}$, Fantinato $\mathrm{S}$, Calonaci F, Cosmi E, Filippeschi M, Zerbetto I, et al. A randomized controlled study comparing harmonic versus electrosurgery in laparoscopic myomectomy. Fertil Steril 2010;94:1882-6. [CrossRef]

25. Amaral JF, Chrosteek CA. Experimental comparison of the ultrasonically activated scalpel to electrosurgery and laser surgery for laparoscopic use. Min Invasive Ther Allied Technol 1997;6:324-31. [CrossRef]

26. Amarin NS. Harmonic Scalpel and Clipless Cholecystectomy. World Journal of Laparoscopic Surgery 2008;1:6-8. [CrossRef]

27. Foschi D, Cellerino P, Corsi F, Previde P, Allevi R, Trabucchi E. Closure of the cystic duct by ultrasonic energy: an electronmicroscopic and biomechanical study in man. Surg Laparosc Endosc Percutan Tech 2009;19:34-8. [CrossRef]

28. Hüscher CG, Lirici MM, Di Paola M, Crafa F, Napolitano C, Mereu A, et al. Laparoscopic cholecystectomy by ultrasonic dissection without cystic duct and artery ligature. Surg Endosc 2003;17:442-51. [CrossRef] 